\title{
CADEIAS PRODUTIVAS SUSTENTÁVEIS
}

\author{
Alexandre de Avila Leripio, DR. (UNIVALI); \\ Daiana Censi Leripio (UNIVALI)
}

\author{
PALAVRAS CHAVES \\ design; sustentabilidade; cadeias produtivas \\ KEY WORDS \\ design; sustainability; production chains
}

\begin{abstract}
RESUMO
Este artigo apresenta uma adaptação das cinco dimensões da sustentabilidade adotadas por Sachs (1993) à estrutura organizacional aplicada ao negócio. Quanto à dimensão social, ressalta-se a ética para com os colaboradores e a comunidade; na dimensão econômica, prevê-se o alicerce financeiro necessário a continuidade do negócio; a dimensão ecológica, por sua vez, pauta-se na inserção equilibrada do negócio no ecossistema; a dimensão espacial indica a utilização racional dos recursos naturais disponíveis; e, por fim, na dimensão cultural, busca-se a valorização do capital intelectual das organizações. Com base nessa fundamentação teórica e na aplicação dos conceitos de Produção Mais Limpa $(\mathrm{P}+\mathrm{L})$; Design for Environment (DFE) para Produtos; Extended Product Responsability (EPR); Logística Reversa; e Zero Emissions Research Iniciative (ZERI) é proposta uma possível sequência de estágios voltados para o desenvolvimento de estratégias sustentáveis em cadeias produtivas, sendo eles: a) conformidade legal: atendimento pleno à legislação; b) conformidade normativa: atendimento às normas técnicas existentes; c) Gestão de riscos, Eficiência e Produtividade: com vistas à redução de riscos, custos e desperdícios; e d) Negócio Sustentável: estruturação da cadeira produtiva completa pautada na transparência.
\end{abstract}

\section{ABSTRACT}

This article presents an adaptation of the five dimensions of sustainability adopted by Sachs (1993) to the organizational structure applied to business. With regards to the social dimension, the ethics toward employees and the community is emphasized; in the economic dimension, the financial foundation necessary to allow for business continuity is considered; the ecological dimension, in turn, focuses in the balanced integration of the business in the ecosystem; the spatial dimension indicates the rational use of available natural resources; and finally, the cultural dimension, seeks the enhancement of intellectual capital of organizations. Based on this theoretical foundation and application of the concepts of Cleaner Production (CP); Design for Environment (DFE) for products; Extended Product Responsibility (EPR); Reverse logistics; and Zero Emissions Research Initiative (ZERI), a possible sequence of stages geared to the development of sustainable strategies in supply chains is proposed, namely: a) legal compliance: full compliance with the law; b) regulatory compliance: compliance with existing technical standards; c) Risk, Efficiency and Productivity Management: in order to reduce risks, costs and waste; d) Sustainable Business: structuring the complete production chain based on transparency. 


\section{INTRODUÇÃO}

A necessária mudança dos valores e da orientação dos sistemas produtivos será decorrência de uma mudança na percepção das pessoas que compõem uma organização, o que pode ser executado através de dois elementos básicos: por consciência (sentido de necessidade) ou por espírito empreendedor (sentido de oportunidade).

Dessa forma, deve-se adotar como referenciais, por um lado a questão relativa aos impactos ambientais e prejuízos socioambientais decorrentes dos processos de produção e consumo, que precisam ser minimizados ou eliminados, e por outro lado a visão da oportunidade da geração de novos negócios a partir dos problemas atualmente gerados. Nesse contexto, os resíduos e subprodutos, tratados como perdas e desperdícios, são os alvos principais a serem eliminados.

O principal fator motivacional para as empresas mudarem sua "percepção" a respeito dos impactos ambientais que seus resíduos geram é a busca da Sustentabilidade do Negócio ou sobrevivência do negócio em uma interpretação livre.

Figura 1 - As cinco dimensões da sustentabilidade.

\section{CONCEITOS E PREMISSAS ADOTADOS PARA A ABORDAGEM DA SUSTENTABILIDA- DE}

A expressão sustentabilidade como apresentada neste texto é fundamentada na abordagem de Sachs (1993), que preconiza a existência de cinco dimensões da sustentabilidade. Baseado em autores e conceitos inovadores á época (e ainda hoje, frente a um sistema cartesiano), tais como o preceito sistêmico de Bertallanffy e o caos auto-organizador de Morin, além de outros, Sachs enunciou as cinco dimensões da sustentabilidade do ecodesenvolvimento, como denominado pelo próprio autor: social, econômica, ecológica, espacial e cultural, como mostra a Figura 1.

A abordagem proposta neste texto contempla uma discussão sobre a visão integrada dos diversos aspectos mencionados pelo sociólogo francês (Sachs, 1993) a serem considerados para a construção de um enfoque sustentável para as organizações, partindo dos mesmos pressupostos tratados pelo autor.

Para Sachs (2000), a dimensão social da sustentabilidade está relacionada com a distribuição justa de renda, a disponibilidade de empregos, boa qualidade de vida e igualdade no acesso aos recursos e serviços sociais. Nesse mesmo enfoque, o agir comunicativo de Habermas faz parte do embasamento ético da sustentabilidade, contemplando a possibilidade de escolhas moralmente adequa $\neg$ das, pois são compartilhadas pelo senso de justiça e

\section{Sustentabilidade social}

Sustentabilidade cultural

Sustentabilidade espacial

\author{
Sustentabilidade \\ econômica
}
Sustentabilidade ecológica


interesse comum, e a ética do discurso, onde todos têm a mesma possibilidade e legitimidade de participar da elaboração e definição de normas que integrem os interesses de todos os indivíduos e organizações afetados direta ou indiretamente, conforme tratado pelos autores Bassani e De Carvalho (2004), De Camargo e Pinheiro (2010), Englund, ÖHman e Östman (2008) e ainda Habermas (1989).

Uma abordagem aplicada ao negócio, adaptação de Leripio (2001) da Dimensão Social da Sustentabilidade proposta por Sachs, teria a seguinte premissa: "O negócio tem que ser gerador de emprego e renda, bem como proporcionar a melhoria da qualidade de vida da comunidade". Ou seja, o negócio é ético com seus colaboradores e com a comunidade.

A dimensão econômica da sustentabilidade garante o alicerce financeiro necessário para a continuidade de um negócio, sendo a capacidade de modernização e a autonomia em pesquisa e tecnologia, igualmente importantes na condução de um processo de desenvolvimento econômico equilibrado (SACHS, 2000). O "capitalismo natural" de Hawken, Lovins e Lovins (1999) está alinhado com a sustentabilidade econômica no momento em que alerta, por um lado, para a interdependência fundamental entre a produção e o uso do capital produzido pelo homem, e por outro, a conservação e o fornecimento do capital natural. Este último constituído de recursos, sistemas vivos e de serviços dos ecossistemas, os quais ainda não são contabilizados em sua totalidade pelo capitalismo tradicional.

Em termos da dimensão econômica, Leripio (2001), alicerçado nos fundamentos do desempenho sustentável (Kinlaw, 1998), lança a premissa básica para a face econômica da sustentabilidade: “Os negócios têm que ser lucrativos". O lucro de um negócio pode ser maior a partir da economia gerada com a eliminação de desperdícios, por exemplo, do que com o aumento de preços, que o mercado regula.

Para Sachs (1993), a sustentabilidade em sua dimensão ecológica compreende a intensificação do uso dos potenciais inerentes aos variados ecossistemas, compatível com sua mínima deterioração e garantindo a capacidade de resiliência dos mesmos. $O$ repensar sobre o paradigma vigente e a evolução da sustentabilidade ecológica tiveram elementos que foram e continuam sendo fundamentais para a compreensão de uma visão holística da sociedade, provenientes de reflexões teóricas da década de 70, conforme mencionado por De Almeida Jr (2000):

a) Herman E. Daly com suas críticas ao pensamento econômico convencional e a ruptura para uma economia em estado de equilíbrio dinâmico, garantindo o respeito às propriedades do ambiente e ética com o ser humano;

b) Fritjof Capra e suas análises sobre o "antigo versus novo" paradigma de percepção, pensamento e ação do homem, e suas implicações éticas, sociais, econômicas, ambientais e políticas;

c) James Lovelock com a hipótese Gaia, de que os sistemas físico-químicos da Terra gozam de interdependência com os sistemas vivos.

Ainda é possível acrescentar à fundamentação teórica desses autores as análises empíricas sobre a situação mundial, organizadas por Lester Brown (State of the World), publicadas anualmente, a partir de 1984, pelo Worldwatch Institute, contribuindo para a consolidação da dimensão ambiental da sustentabilidade e conforme Gleick (1989), “Uma explicação da natureza substitui outra. Velhos problemas são vistos sob uma luz nova e outros problemas são identificados pela primeira vez".

A interpretação aplicada ao negócio sustentável da dimensão ecológica da sustentabilidade conforme Leripio (2001) se reflete na afirmação: "O negócio tem que estar inserido de forma equilibrada no ecossistema", ou seja, ele se integra de forma harmônica aos processos ecossistêmicos e aos fluxos de matéria e energia existentes em sua área geográfica de atuação.

A propósito do território em si, o equilíbrio entre as configurações urbanas e rurais, com ressalvas á concentração geográfica, foi 
disseminado por Sachs (2000) para o alcance da sustentabilidade do espaço ou dimensão espacial da sustentabilidade. Os investimentos públicos em infraestrutura, fortemente destinados às zonas urbanas, promovem desigualdades quando analisadas as iniciativas para habitação, saneamento, educação, saúde e transportes nas zonas rurais, estas pouco incentivadas. Martine (2007) preconiza o uso sustentável do espaço na relação intitulada de população/desenvolvimento/ambiente (PDA). De forma geral, o autor conduz à reflexão da necessidade de uma abordagem holística, a qual considere a interação entre os diferentes usos da terra e os fatores ecológicos específicos de cada região. Ward e Dubos (1972) contribuíram com o lema adotado pela Agenda 21, "pensar globalmente, agir localmente", considerando uma visão cósmica e humanista da ocupação e desenvolvimento do espaço geográfico.

Sobre essa temática, uma questão para reflexão que pode gerar polêmica e controvérsias, considerando os diferentes pontos de vista possíveis: "toda empresa sustentável nasce pequena e com atuação local e se torna grande e global conforme seus produtos ou serviços se tornem imprescindíveis em outros mercados"?

Para contemplar a sustentabilidade espacial, em relação ao negócio, a adaptação de Leripio (2001) aponta para a seguinte afirmação: "O negócio tem que utilizar racionalmente os recursos naturais existentes e disponíveis em sua área de atuação". Cabe uma ressalva à expressão "racionalmente", devido ao caráter relativo da mesma, ou seja, uma decisão racional para empresários "sem percepção ou com pouca percepção para a sustentabilidade" pode ser algo muito diferente do que uma decisão racional de empresários mais evoluídos, ou seja, com percepção mais desenvolvida em relação ás dimensões social, cultural, espacial e ecológica além da econômica. Portanto, no contexto proposto, racionalidade parte do pressuposto conservacionista, ou seja, usar com racionalidade significa usar o recurso de forma a não esgotá-lo ou extingui-lo e com isso manter a provisão continuada de matérias primas para o negócio.

Sachs (2000) ao incluir em sua proposta a garantia do respeito às especificidades dos ecossistemas de cada local, corrobora a cultura como fato indissociável da sustentabilidade. Maia (2007), afirma que o processo de globalização conduziu a uma necessidade ampla da valorização das culturas locais, como garantia de diferencial e competitividade frente às diversas regiões e países que comercializam no mercado internacional. A pluralidade de culturas e tradições associada à busca de inovações, permite a coexistência de diferentes produtos e serviços propostos para variados públicos e interesses. No fenômeno administrativo, a influência do contexto histórico cultural dos indivíduos na cultura organizacional foi amplamente relatada por diversos autores, tais como Guerreiro Ramos (1983), Prestes Motta e Caldas (1997), Barros e Patres (1996) e ainda Serva (1990). Maturana e Varela (2001) explicam a "conduta cultural" como a estabilidade do comportamento entre as gerações, adquirida por meio das dinâmicas de comunicação, inerentes aos meios sociais.

Segundo Leripio (2001), em termos de organizações produtivas a dimensão cultural da sustentabilidade pode ser traduzida pela seguinte expressão: "Os negócios têm que ser independentes de tecnologias de produção importadas e de monopólios de fornecimento". Isso significa fomentar a "raiz endógena dos processos criativos" como diria Sachs, ou seja, valorizar o capital intelectual das organizações.

Por fim, a sustentabilidade temporal, proposta adicionalmente por Leripio (2001), embora implícita nas colocações do sociólogo francês, pode ser explicitada pela seguinte afirmação, aplicada à realidade das empresas e suas relações com o estoque de recursos naturais: "O negócio pode ser mantido ao longo do tempo, sem restrições ou escassez de insumos e matérias primas". Se o negócio utiliza recursos renováveis como matéria-prima, que promova ações de conservação de sua capacidade regenerativa ou respeite seu ciclo natural, caso utilize matérias primas oriundas de recur- 
sos naturais não renováveis, que proporcione o "fechamento de ciclos", de forma a manter sempre a viabilidade do negócio a partir da reciclagem dos produtos pós-consumo, por exemplo como faz a indústria do alumínio no Brasil e no mundo.

Portanto, segundo os autores referenciados, para que uma organização rume em direção á sustentabilidade ela deve:

- assumir um compromisso no âmbito de sua rede de relações (responsabilidade social corporativa);

- produzir produtos de melhor qualidade, com menor poluição e menor uso dos recursos naturais (ecoeficiência);

- analisar o ciclo de vida dos produtos, bem como os impactos ambientais resultantes das atividades de produção em toda a cadeia produtiva;

- formar parcerias empresariais tendo como objetivo a formação de complexos industriais sistêmicos, onde os resíduos sejam transformados em novos recursos, imitando os ecossistemas naturais (emissão zero);

- aderir aos sistemas de gestão certificáveis;

- aplicar continuamente estratégias ambientais aos processos e produtos, com o intuito de reduzir riscos ao meio ambiente e ao ser humano (produção mais limpa);

- desenvolver relatórios de sustentabilidade corporativa, bem como os acionistas da empresa devem governar seu negócio, otimizando o desempenho da empresa e facilitando o acesso ao capital (governança corporativa).

Deste modo, respeitando esses princípios e adotando tais métodos, a organização estará a caminho da sustentabilidade, ou seja, poderá garantir sua sobrevivência em um mercado cada vez mais competitivo. Como se percebe nos itens listados, não basta a organização "olhar para dentro". É fundamental que se inicie a busca pela sustentabilidade em caráter interno, mas a inserção de uma organização em uma cadeia produtiva diz muito sobre o real estágio de sustentabilidade alcançado pela mesma. $\mathrm{O}$ item a seguir explora melhor essas relações.

\section{SUSTENTABILIDADE EM PROCESSOS E CA- DEIAS PRODUTIVAS}

Uma cadeia de produção, para Batalha (1997), pode ser definida a partir da identificação de um produto final qualquer. Após a identificação ter sido realizada, cabe ir encadeando, do fim (jusante) ao começo (montante), as várias operações técnicas, comerciais e logísticas necessárias para a sua produção.

O conceito de cadeias produtivas está intimamente ligado ao conceito de clusters, que segundo Pires (2001) é normalmente parte inicial dos estudos de avaliação da cadeia produtiva, onde geralmente estes conceitos se confundem, sendo que os clusters são concentrações geográficas de algumas partes da cadeia produtiva.

Diversas estratégias e instrumentos são aplicáveis quando o objetivo é promover a sustentabilidade em processos e cadeias produtivas. Algumas das mais destacadas serão apresentadas a seguir.

\subsection{RESÍDUOS, PROCESSOS E CADEIAS PRO- DUTIVAS}

Os restos das atividades humanas, considerados como inúteis, indesejáveis ou descartáveis, são chamados de resíduos (MISSIAGGIA, 2002). A classificação destes "restos" como resíduo varia de acordo com o espaço, tempo e cultura.

Os problemas associados aos resíduos, segundo Figueiredo (1995), decorrem de dois componentes principais: a crescente geração de resíduos e a evolução "qualitativa" dos mesmos. Quanto ao primeiro componente, o rápido crescimento ocorre em função tanto do crescimento populacional e seu adensamento espacial, quanto do aumento da geração per capita de resíduos, imposto pelos padrões de propaganda, que intensificam a associação do consumo à qualidade de vida. Com relação ao segundo componente, a evolução na composição da massa de resíduos se deve a evolução dos materiais empregados pela sociedade. 
Para a busca de uma gestão ambiental focalizada em resíduos, no intuito de superar a ineficiência de processos e cadeias produtivas, é indispensável perseguir os seguintes pressupostos citados em Oliveira (2002):

- princípio de sustentabilidade (na dimensão) ambiental: a política deve ser orientada para a obtenção de um comportamento dos agentes geradores dos resíduos e responsáveis pelos mesmos em todas as etapas de seu ciclo de vida, de forma a minimizar o impacto sobre o meio ambiente, preservando-o como um conjunto de recursos disponíveis em iguais condições para as gerações presentes e futuras;

- princípio do "poluidor-pagador": essencial na destinação dos custos de prevenção da contaminação, este princípio estabelece que são os geradores de resíduos, os agentes econômicos, as empresas industriais e outras, que devem arcar com o custeio que implica no cumprimento das normas estabelecidas;

- princípio da precaução: o princípio sustenta que a autoridade pode exercer uma ação preventiva quando há razões para crer que as substâncias, os resíduos, ou a energia, introduzidos no meio ambiente podem ser nocivos para a saúde ou para o meio ambiente;

- princípio da responsabilidade "do berço ao túmulo": o impacto ambiental do resíduo é responsabilidade de quem o gera, isto é, a partir do momento em que o produz, até que o resíduo seja transformado em matéria inerte, eliminado ou depositado em lugar seguro, sem risco para a saúde ou o meio ambiente;

- princípio do menor custo de disposição: este princípio define uma orientação dada pela Convenção da Basiléia, em 1989, para que as soluções que se adotem em relação aos resíduos minimizem os riscos e custos de traslado ou deslocamento, fazendo como que, dentro do possível, os resíduos sejam tratados ou depositados nos lugares mais próximos de seus centros de origem;

- princípio da redução na fonte: sustenta a conveniência de evitar a geração de resíduos mediante o uso de tecnologias adequadas, tratamento ou minimização em seu lugar de origem;
- princípio do uso da melhor tecnologia disponível: é um princípio pouco aplicável em países como o Brasil que possui dependência tecnológica.

\subsubsection{PRODUÇÃO MAIS LIMPA (P+L)}

O conceito de "Produção Mais Limpa" (Cleaner Production) teve sua origem e ganhou visibilidade a partir de 1989, quando o Programa das Nações Unidas para o Meio Ambiente (PNUMA) criou o programa de Produção Mais Limpa, visando racionalizar a produção industrial.

A Produção Mais Limpa $(\mathrm{P}+\mathrm{L})$ envolve aplicação contínua de estratégias ambientais aos processos e produtos de uma indústria, com o intuito de reduzir riscos ao meio ambiente e ao ser humano. Esta estratégia visa prevenir a geração de resíduos, efluentes e emissões, bem como minimizar o consumo de matérias-primas e energia (Furtado, 1999).

A P+L, segundo Rigola (1998), se aplica aos:

- processos de produção: pois conserva as matérias-primas e energia, elimina matérias-primas tóxicas e reduz a quantidade e toxicidade de todas as emissões e resíduos;

- produtos: pois reduz os impactos negativos ao longo do ciclo de vida de um produto, desde a extração das matérias-primas até sua disposição final, e

- serviços: pois incorpora a preocupação ambiental no projeto e execução de serviços.

Almeida (2002) insere a implantação de um programa de $\mathrm{P}+\mathrm{L}$ em três etapas. A primeira concentra-se na identificação de oportunidades de redução de poluição na fonte e no que se chama de housekeeping (arrumação da casa), ou seja, medidas pontuais, que exigem pouco ou nenhum investimento econômico e em geral dão retorno imediato ou em curto prazo. Já a segunda etapa significa introduzir mudanças no processo de produção. Exige investimento econômico de baixo a médio e o retorno é em curto ou médio prazo. $E$, finalmente, a terceira etapa incorpora mudanças tecnológicas e/ou de design de produto. $\mathrm{O}$ investimento econô- 
mico é de médio a grande e o retorno é a médio e longo prazo.

Alguns dos incentivos que uma empresa desfruta na aplicação da $\mathrm{P}+\mathrm{L}$ são abordados por Rigola (1998) e segundo esse autor, compreendem:

- o cumprimento da legislação presente ou previsível em um futuro próximo;

- obtenção de benefícios econômicos na exploração e aumento da competitividade;

- melhora da imagem empresarial e, associada a ela, estabelecimento de melhores relações com os clientes, vizinhos e a sociedade em geral; e

- redução de possíveis responsabilidades civis e penais; aperfeiçoamento das condições de trabalho no que diz respeito à higiene e segurança, e redução de necessidades de tratamento de efluentes, deixando capacidade disponível nas instalações para futuros projetos de ampliação e reduzindo a inversão que seria necessária.

Além disso, essas melhorias podem se transformar em vantagens perante negociações de prêmio de seguros juntos às companhias seguradoras.

Conforme Schmidheiny (1992), existem três impedimentos principais que servem como barreiras para a adoção de posturas ambientalmente corretas: as preocupações econômicas, a falta de informações e as atitudes dos gerentes. Assim, segundo Rigola (1998), a adoção da P+L pode apresentar algumas dificuldades, como:

- falta de consciência ambiental;

- típica resistência burocrática a introduzir qualquer tipo de troca;

- falta de suporte empresarial por parte dos altos níveis de gestão;

- falta de informação sobre as possibilidades e vantagens existentes na $\mathrm{P}+\mathrm{L}$;

- falta de tecnologia apropriada;

- prevenção por parte dos responsáveis pela pesquisa, desenvolvimento, engenharia ou produção;

- incorreta consignação dos custos de tratamento ou disposição final que não permitem refletir os benefícios econômicos;

- falta de recursos financeiros;
- falta de internalização dos custos ambientais.

A $\mathrm{P}+\mathrm{L}$ se apresenta como uma atividade sistemática e permanente por facilitar uma resposta contínua às novas situações a que a empresa se expõe. Contudo, a $\mathrm{P}+\mathrm{L}$ proveitosa para o meio ambiente e a economia, tem determinadas limitações em cada setor industrial. Rigola (1998) menciona a possibilidade de reduzir em até $30 \%$ os problemas ambientais através da $\mathrm{P}+\mathrm{L}$, no entanto existe um grande caminho a percorrer até alcançar os objetivos de uma iniciativa como a emissão zero, por exemplo, que será apresentada em um próximo item.

Para Figueiredo (1995), a preocupação com a reintegração dos resíduos à cadeia cíclica dos materiais no planeta inclui muitos aspectos que vão desde a escolha dos componentes utilizados pelo setor produtivo até a distribuição espacial associada ao consumo.

O mesmo autor aponta que a despeito dos vários problemas ocorridos ao longo da história, em nenhum momento a questão dos resíduos foi tratada com seriedade. Mais recentemente, por representar uma ameaça real ao meio ambiente e, consequentemente, ao próprio homem, os resíduos vêm conquistando a atenção mundial, especialmente no que diz respeito ao processamento, transporte e à disposição final, além do questionamento da sociedade e das autoridades acerca da intensidade de geração e das possibilidades e limitações no seu reaproveitamento por parte dos próprios fabricantes.

\subsubsection{DESIGN FOR ENVIRONMENT (DFE) PARA PRODUTOS}

O Projeto para o Meio Ambiente (DFE, por sua sigla em inglês Design For Enviroment) significa fazer das considerações ambientais uma parte integral do processo de projeto de produtos, com o objetivo de facilitar a reciclagem de um produto, assim como adaptar os novos materiais e processos, na melhoria e criação de novos produtos.

O DFE usa os conceitos de ciclo de vida 
juntamente com algumas estratégias a fim de reduzir o impacto ambiental. As estratégias apresentadas nesta perspectiva, citadas por Manzini \& Vezzoli (2005) são as seguintes:

- minimização dos recursos: reduzir o uso de materiais e de energia;

- escolha de recursos e processos de baixo impacto ambiental: selecionar os materiais, os processos e as fontes energéticas de maior ecocompatibilidade;

- otimização da vida dos produtos: projetar artefatos que perdurem. Esta estratégia está relacionada, mais propriamente, às fases de distribuição (embalagem), uso e de descarte/eliminação;

- extensão de vida dos materiais: projetar em função da valorização (reaplicação) dos materiais descartados. Esta estratégia é própria da fase de descarte/eliminação;

- facilidade de desmontagem: projetar em função da facilidade de separação das partes e dos materiais. Este preceito é funcional para a otimização da vida dos produtos e para a extensão da vida dos materiais.

Para Manzini \& Vezzoli (2005), as decisões mais importantes e influentes, de um design ambientalmente consciente são tomadas nas primeiras fases do projeto. É importante, portanto, introduzir e integrar as questões e os requisitos ambientais desde o início do processo de desenvolvimento de um produto ou de um serviço. Assim, para que essas estratégias citadas sejam eficazes, elas devem ser aplicadas somente depois da definição dos objetivos do projeto e dos requisitos daí derivados.

Evidentemente, ainda segundo os autores acima, quem projeta - para evitar estratégias e escolhas enganosas, e para visualizar e focalizar com um certo grau de confiança os âmbitos mais significativos em que é preciso intervir - deve ter, desde o início, as informações e os instrumentos de decisão necessários. Quem projeta tem de possuir informações e os instrumentos e métodos de análise, de medida, de avaliação e, até mesmo, instrumentos de suporte para as suas decisões.

As escolhas que os projetistas fazem durante o desenvolvimento de um produto novo ou melhorado, determinarão o impacto ambiental durante cada fase do ciclo de vida do produto, desde a aquisição de materiais passando pela manufatura, uso, reuso e finalmente o descarte final do produto. Os mesmos podem avaliar também o desempenho ambiental de seus produtos e propor soluções muito originais aos interesses ambientais, ou eles podem ainda ajudar a sintetizar as melhorias que agora incluem interesses ambientais (PRATES, 1998).

\subsection{Estratégias e Instrumentos para a Sus- tentabilidade das Cadeias Produtivas}

No momento em que as organizações cumprirem ações internas voltadas á melhoria de processos, seu foco pode e deve se voltar á cadeia produtiva que atua. De forma a fundamentar as abordagens de cadeias produtivas sustentáveis, serão apresentadas algumas estratégias e/ou instrumentos apropriados a tal finalidade.

\subsubsection{DESIGN DE PROCESSOS E CADEIAS PRODUTIVAS}

O desenvolvimento de produtos limpos pode requerer tecnologias limpas, mas certamente, requer uma nova capacidade de design (de fato, é possível chegar a produtos limpos mesmo sem muitas sofisticações tecnológicas). De maneira semelhante, porém mais acentuada ainda, a busca da promoção do consumo e do comportamento limpos exige novos produtos, podendo também direcionar a orientação das escolhas para um novo mix de produtos e serviços que para serem aceitos, dependem de uma mudança na cultura e no comportamento dos usuários. Nesse âmbito, portanto, propor soluções que apresentem uma alta qualidade ambiental não pode prescindir do quanto, e como, elas sejam social e culturalmente aceitáveis (MANZINI \& VEZZOLI, 2005).

Dentro desse quadro geral de referência, para Manzini \& Vezzoli (2005), o papel do design pode ser sintetizado como a atividade que, li- 
gando o tecnicamente possível com o ecologicamente necessário, faz nascer novas propostas que sejam social e culturalmente apreciáveis. Uma atividade que possa ser articulada, conforme o caso, em diferentes formas, cada uma delas dotada de suas especificidades.

Os objetivos do Projeto para o Meio Ambiente visando o aprimoramento dos processos e cadeias produtivas, na busca do menor impacto ambiental e apoiando o crescimento sustentável, são apresentados conforme Prates (1998):

- Análise do projeto: inclui um número de atividades inter-relacionadas, as quais pretendem avaliar sistematicamente as opções de projeto;

- Identificação do perfil ambiental: fornecem ao projetista uma boa indicação por onde começar a revisão de possíveis estratégias de projetos;

- Estratégia de projeto: uma vez que a fase de ciclo de vida dominante é identificada, o projetista deverá avaliar as opções de projeto inicial juntamente com as estratégias definidas;

- check-list de ciclo de vida: esses questionários são desenvolvidos para ajudar os projetistas a incluir as considerações ambientais associadas com as estratégias de melhoria;

- Análise de opção de projeto: a proposta é atentar para identificar as opções de projeto com o maior potencial para a competitividade ambiental;

- Otimização de projeto: cada uma das opções de projeto analisadas pode ser acoplada com outras considerações e avaliadas juntamente com os objetivos do projeto. Fazer escolhas entre as opções é uma característica regular da atividade de projeto.

Manzini e Vezzoli (2005) prescrevem que o design para a sustentabilidade deve aprofundar suas propostas na constante avaliação comparada das implicações ambientais, nas diferentes soluções técnica, econômica e socialmente aceitáveis e deve considerar, ainda, durante a concepção de produtos e serviços, todas as condicionantes que os determinem por todo o seu ciclo de vida. As mudanças necessá- rias à transição para a sustentabilidade são de ordem sistêmica e, portanto, exigem inovações não somente tecnológicas, mas também sociais e culturais e em toda a cadeia produtiva.

\subsubsection{RESPONSABILIDADE ESTENDIDA DO PRODUTOR}

As primeiras legislações ambientais do início dos anos 70 seguiam a tendência de responsabilizar os governos locais pelo impacto ambiental causado pelos resíduos sólidos pós-consumo. No entanto, mais recentemente, as legislações tendem a responsabilizar os fabricantes, direta ou indiretamente, pelo impacto de seus produtos no meio ambiente, por meio de leis dirigidas às etapas de reciclagem ou, indiretamente, por meio de proibições de disposição em aterros sanitários e do uso de certos tipos de embalagens plásticas até a devida estruturação dos canais reversos. Essas legislações têm sua origem nas idéias da denominada filosofia de EPR (Extended Product Responsability) (LEITE, 2009).

A Responsabilidade Estendida do Produtor é uma das mais significativas tendências normativas atualmente encontradas no cenário europeu e internacional. Sua definição mais difundida e aceita foi proposta por pesquisadores da Universidade de Lundt:

A extensão da responsabilidade do produtor é uma estratégia visando à redução do impacto ambiental de um produto, tornando o produtor responsável pelo ciclo de vida total do produto e, em particular, pela recuperação, pela reciclagem e pela digestão dos resíduos finais. A extensão da responsabilidade pode ser implementada através de instrumentos administrativos, econômicos e informativos. A composição desses instrumentos determina a fórmula precisa da extensão da responsabilidade (UNIVERSITY OF LUNDT, 1992 APUD MANZINI \& VEZZOLI, 2005). 
O ciclo de vida do produto, segundo Mourad et al. (2002), inicia-se quando os recursos para a sua fabricação são removidos de sua origem, a natureza - o berço, e finaliza-se quando o material retorna para a terra, o túmulo. O chamado princípio EPR fundamenta a idéia de estender a toda a cadeia industrial direta a responsabilidade de reduzir os impactos de seus processos e produtos no meio ambiente, atribuindo ao produtor a responsabilidade pelo produto durante todo o seu ciclo de vida, "do berço ao túmulo". O ciclo de vida de um produto, no contexto do EPR pode ser observado na figura 2 a seguir.

No âmbito da EPR, esta poderia expan-

Figura 2 - Responsabilidade Estendida do Produtor segundo a perspectiva do Ciclo de vida.

EXTENDED PRODUCT RESPONSABIUTY - PERSPECTIVA DO CICLO DE VIDA (LCA)

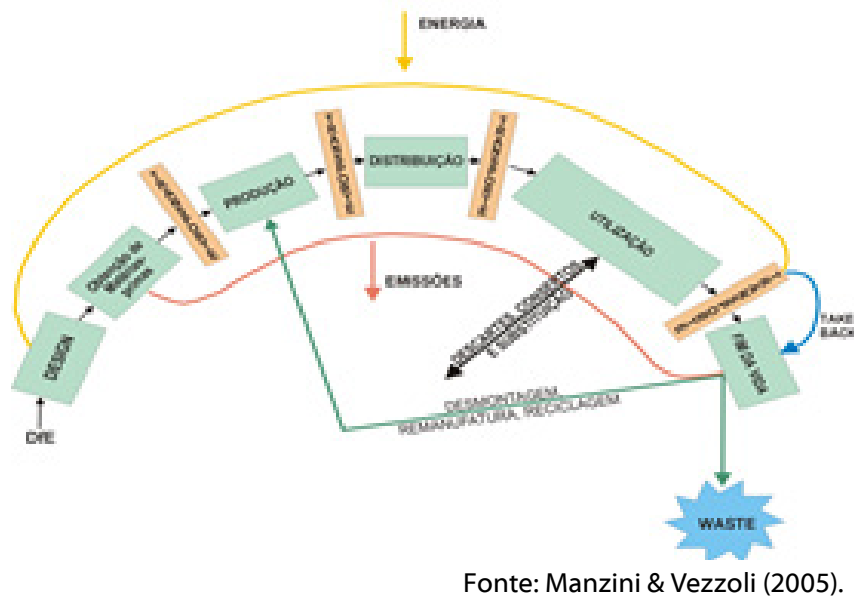

dir-se ao ciclo inteiro de vida do produto, conforme sugerem Manzini \& Vezzoli (2005), abrangendo não somente a produção e a valorização de seu fim de vida, mas também na sua correta gestão durante seu período de vida útil. O produtor tenderia, assim, a mudar de papel e posicionar-se também como um operador, cujo trabalho não mais derive apenas da venda dos seus produtos, mas também, da venda dos resultados deles (mobilidade, entretenimento, limpeza da casa e do vestuário...), ou seja, uma empresa fabricante de condicionadores de ar não venderia mais o direito de propriedade do aparelho ao cliente, mas o direito de uso por tempo pré-determinado (fim estimado da vida útil), ou ainda o fabricante ou seu representante poderia prestar serviços de "climatização de ambientes", por meio dos aparelhos produzidos, de posse/propriedade/responsabilidade do fabricante. Quando o aparelho estraga, é obrigação do prestador de serviço repor o equipamento danificado. Com isso, o consumidor se desobriga de ter que consertar ou dar destino adequado a um equipamento que, de posse de seu fabricante, pode ser recondicionado e reinserido na cadeia produtiva. Para que isso aconteça, a própria logística terá que ser adaptada.

\subsubsection{LOGÍSTICA REVERSA}

O conceito de logística começou a aparecer no inicio da década de 40 do século passado, devido principalmente á sua utilização pelas forças armadas norte-americanas na segunda grande guerra mundial. Em 1948, segundo Colin e Porras (1996), a logística foi definida pela American Marketing Association como a forma de movimentação e manutenção de mercadorias do ponto de produção ao ponto de consumo ou de utilização.

Para Ching (1999), nas décadas de 80 e 90, o foco da logística passou a ser de agregar maior valor ao cliente, na qual a integração da cadeia logística (supply chain), tornou-se elemento fundamental para a conquista de vantagens competitivas. Segundo o mesmo, a integração da cadeia logística concentra-se em alinhar os processos-chave do negócio de montante (fontes supridores de insumos) até jusante (consumidores).

Uma cadeia de suprimento (Supply Chain) pode ser vista de acordo com Slack (1997), como uma cadeia sequenciada de unidades produtivas dentro de uma rede de suprimentos de uma organização, a qual passa pela própria organização. Segundo o mesmo autor, uma rede de suprimentos se dá quando todas as operações formam uma rede de fornecedores para fornecedores e 
clientes para clientes, sendo que todas as operações, que fazem parte de uma rede maior de clientes e fornecedores, podem ser rastreadas para trás em direção ás fontes originais de bens e serviços (montante) e igualmente para a frente em direção aos clientes finais (jusante).

Dentro de uma cadeia de suprimentos, especialmente nas mais longas, erros, anomalias e volatilidades são crescentes para as empresas situadas mais a montante. Com o intuito de racionalizar estas aberrações na cadeia e na busca por melhor qualidade e produtividade, de acordo com Pedrozo e Hansen (2001), é que surgiu a função da logística nas organizações, envolvendo a ligação entre as funções internas e externas da mesma, com os fornecedores diretos e indiretos.

As exigências cada vez maiores de se adequar os processos das organizações à proteção ao meio ambiente faz surgir uma sub-área da logística empresarial, a logística reversa. Esta sub-área, definida pelo Council of Logistics Management (CLM) "engloba práticas de gerenciamento de logística e atividades envolvidas na redução, gerência e disposição de resíduos, incluindo distribuição reversa, que é o processo pelo qual uma companhia coleta seus produtos usados danificados, vencidos ou as embalagens de seus consumidores finais"(SIMÕES, 2002).

Segundo Leite (2009) os canais de distribuição reversos compreendem as etapas, as formas e os meios em que uma parcela dos produtos da empresa, com pouco uso após a venda, com ciclo de vida útil ampliado ou após extinta a sua vida útil, retorna ao ciclo produtivo ou de negócios, readquirindo valor em mercados secundários pelo reuso ou pela reciclagem de seus materiais constituintes.

Leite (2009) define duas categorias de canais de distribuição reversos: os canais de distribuição reversos de pós-consumo e de pós-venda. Os canais reversos de pós-consumo subdividem-se em canais reversos de reuso de bens duráveis e semiduráveis, de desmanche de bens duráveis e de reciclagem de produtos e materiais constituintes. Os canais reversos de pós-venda são constituídos pelas diferentes formas e possibilidades de retorno de uma parcela de produtos, com pouco ou nenhum uso, motivados por problemas relacionados à qualidade em geral ou a processos comerciais entre empresas, retornando ao ciclo de negócios de alguma maneira. Na figura 3 se pode observar o fluxo dos produtos nos canais de distribuição diretos e reversos, desde as matérias-primas virgens até o mercado, entendido como o mercado primário de produtos.

A conscientização ecológica e a busca por um desenvolvimento sustentável, aliados às pressões legislativas de proteção ao meio ambiente e a consequente responsabilidade social por parte das empresas representam fatores de influência no surgimento das cadeias produtivas reversas.

Segundo Leite (2009), observa-se um avanço nas legislações de diversos países, visando responsabilizar as empresas pelo retorno de seus bens e materiais, evitando o impacto disso sobre o meio ambiente.

Como exemplo, podem ser citados o RoHS - Restrictions for Hazardous Substances e o WEEE - Waste from Electrical and Electronic Equipment, exigidos na União Européia a partir de 01/01/2006, baseado na Responsabilidade Estendida do Produtor (EPR). Observa-se também uma maior preocupação dos empresários na busca de competitividade por meio da logística reversa, visto que ela permite uma diferenciação mercadológica de serviço perceptível aos clientes.

A responsabilidade social representa um fator fundamental para a implantação de programas de logística reversa onde a redução de custos não seja significativa ou até mesmo haja o aumento de custos diretos, que são compensados pela redução de impactos negativos na comunidade traduzidos em custos indiretos ou mesmo inatingíveis (SIMÕES, 2002).

Uma cadeia produtiva sustentável não pode, portanto, não se apresentar como um 
Figura 3 - Canais de distribuição diretos e reversos

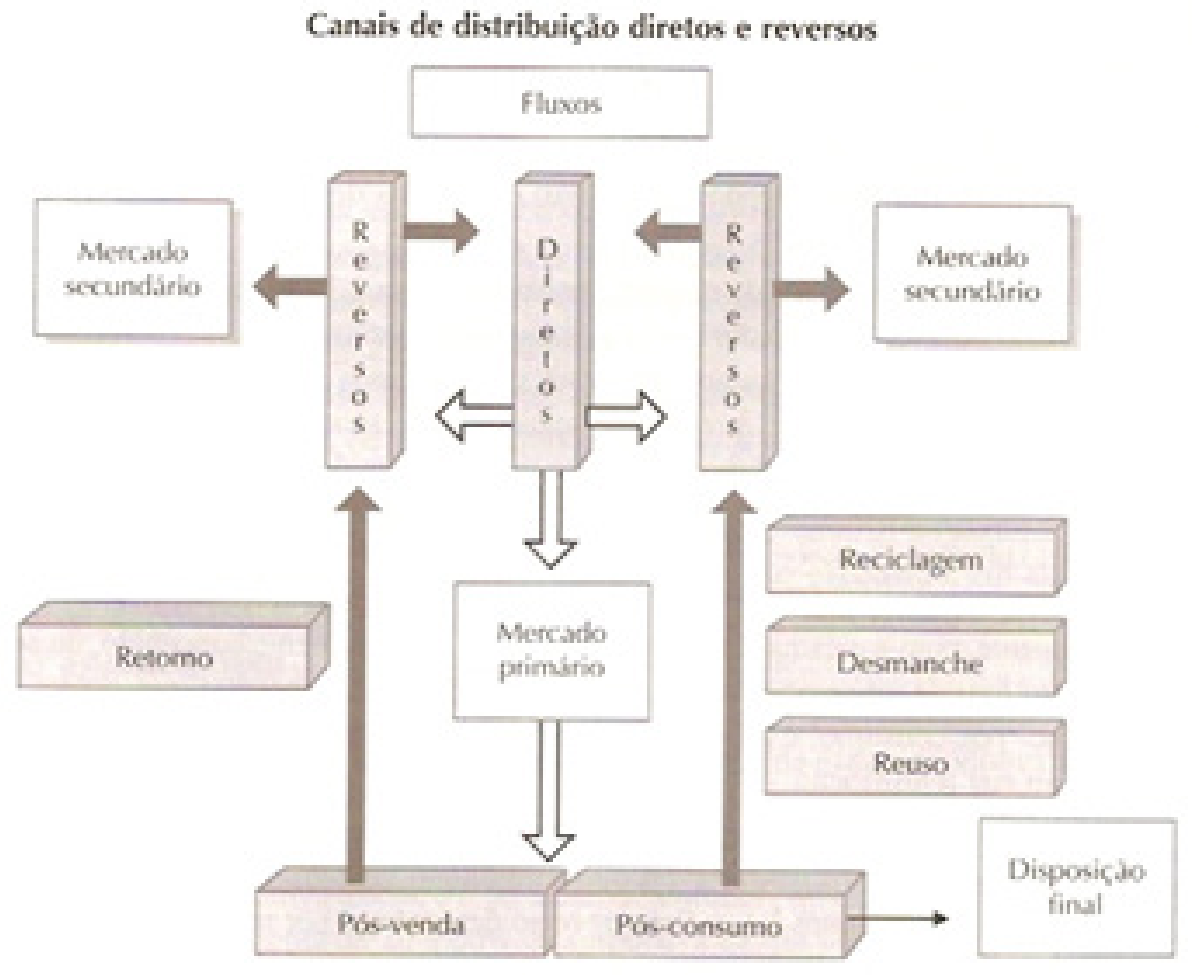

Fonte: adaptado de Leite (2009)

inspiraram o conceito de ZERI foi a intenção de imitar os ecossistemas naturais harmonizando as atividades econômicas com os ciclos biológicos, respeitar as leis da vida sobre o planeta, enquanto se busca o progresso material e bem-estar social, e proporcionar às atuais gerações o que necessitam, sem comprometer as chances de que as futuras gerações tenham 0 mesmo (LERIPIO, 2001).

Nesse contexto, o ZERI emergiu de um processo de cristalização dos ideais do desenvolvimento sustentável proclamados na

ciclo, seja pela renovabilidade de suas matérias primas e biodegradabilidade de seus produtos ou pela reciclabilidade de seus produtos pós-consumo.

\subsubsection{ZERO EMISSIONS RESEARCH INITIATI- VE (ZERI)}

A Iniciativa para a Pesquisa em Emissão Zero (ZERI, por sua sigla em inglês Zero Emissions Research Initiative) foi lançada, em 1994, pela Universidade das Nações Unidas (UNU United Nations University) em Tóquio, no contexto do Programa de Ecoreestruturação para o Desenvolvimento Sustentável (PAULI, 1998).

$O$ ZERI surgiu na UNU como resultado da convergência de três correntes de pensamento que dominaram o cenário mundial nos últimos 60 anos: a desenvolvimentista, voltada para o crescimento econômico e a expansão da produção industrial; a social, atenta ao bem estar humano individual e coletivo, e a ecológica, defendendo os sistemas naturais e a qualidade do meio ambiente.

Um dos princípios fundamentais que
Conferência de Estocolmo e consagrados na Rio-92, e da busca de estratégias apropriadas para promovê-lo.

A metodologia ZERI se apoia, segundo Pauli (1998), em cinco etapas distintas:

- modelos de aproveitamento total: utilização completa de todos os resíduos gerados no próprio processo produtivo;

- modelos de entrada e saída: quando não é possível a transformação total dos materiais de entrada se procede um inventário de todos os componentes de saída, para a análise de possíveis usos;

- modelos de conglomerados industriais: em uma terceira etapa se busca o agrupamento de indústrias que através de novas relações comerciais, podem conseguir um benefício mútuo;

- identificação de novas tecnologias: os agrupamentos industriais podem não ser economicamente viáveis, tendo que identificar as trocas tecnológicas necessárias e lançar programas de investigação para conseguir o objetivo de poluição zero;

- Planejamento de políticas industriais: 
todas as etapas anteriores devem ser acompanhadas por uma política industrial e uma legislação apropriadas que facilitem o progresso e os objetivos marcados.

O ZERI traz a abordagem sistêmica para dentro do conjunto das atividades industriais, contrapondo-se à visão linear tradicional da empresa, na qual o processo produtivo se resume em três estágios: insumo, processo e produto. Analisa o processo produtivo interligado e sugere políticas e estratégias de gestão do sistema econômico e social.

A aplicabilidade do ZERI é enorme, mas tem limitações. A falta de conhecimento, a literatura escassa, a divulgação incipiente e o desafio paradigmático de mudar a mente conservadora, exigem forte colaboração e cooperação entre todas as partes interessadas, governo, academia e setor privado (Leripio, 2001).

A metodologia ZERI, comenta Pauli (1998), fornece um instrumento interessante para muitos setores alcançarem o desenvolvimento sustentável. Os ambientalistas vêem-na como um instrumento para uma redução extraordinária da poluição. O gerenciamento existente utiliza-a para aumentar sua competitividade. Os investidores vêem-na como um instrumento para obtenção de ganhos substanciais de capital em ativos ocultos e se utilizam da metodologia para a identificação de empresas subestimadas que sejam dignas de ser incorporadas. Os governos utilizam a metodologia para a identificação de políticas públicas para o desenvolvimento sustentável de regiões, para as quais um pacote especial de incentivos pode ser planejado. E os cientistas se voltam à metodologia ZERI porque ela oferece um sistema único para integrar diversas disciplinas, todas com interesse na construção de um futuro sustentável, mas que até agora encontraram poucas conexões para a realização de um programa pertencente a todos.

\section{CONVERSÃO DE CADEIAS PRODUTIVAS PARA A SUSTENTABILIDADE}

No contexto empresarial, a discussão da evolução da sustentabilidade e a suas interfaces com as teorias científicas formam um embasamento consolidado e necessário para a elaboração de ferramentas que auxiliem as empresas a construírem uma atuação alinhada com as expectativas das partes interessadas. Apesar das críticas às fórmulas prescritivas do funcionalismo na gestão, destacadas por autores como Clark e Greatbatch (2004), Collins (2000), De Paula e Wood Jr (2003) e Pierce e Newstron (2002), este permite aproximar os conceitos teóricos das necessidades da resolução de problemas práticos das organizações.

Senge (2006) acredita que a sustentabilidade é um termo amplo, análogo a um "guarda-chuva", o qual contempla soluções que contribuem para as organizações lidarem de forma eficaz com suas externalidades causadas pela visão de lucro no curto prazo.

Neste contexto, a sustentabilidade se converte em estratégias e práticas organizacionais, delimitadas por um conjunto de condicionantes socioambientais, na qual a gestão dos riscos envolvidos depende não somente da capacidade técnica e econômica das empresas, mas também de como se organizam para responder tais condicionantes (Amato Neto, 2011). De tal modo, é proposta uma reflexão sobre uma possível sequência de estágios para que as organizações desenvolvam estratégias para se tornarem sustentáveis, considerando neste sentido as dimensões de Sachs (2000) e as teorias científicas abordadas, mas igualmente o âmago da temática que consiste na habilidade de se manter ou conservar um modelo sistemático capaz de se adaptar às mais diversas situações, reforçando a própria definição de capacidade de resiliência dos seres vivos. De forma mais prática, significa a sobrevivência permanente dos empreendimentos humanos e da própria sociedade, pois se relaciona com as condições de vida oferecidas pelo planeta.

A sequência proposta por Leripio para a sustentabilidade das organizações (Figura 4) é 
denominada "Estágios da Estratégia Sustentável de Produção", a qual se fundamenta na busca por vantagens (econômicas inclusive) às organizações que a implementem de forma integral.

Figura 4 - “Estágios da Estratégia Sustentável de Produção", seus objetivos e autores

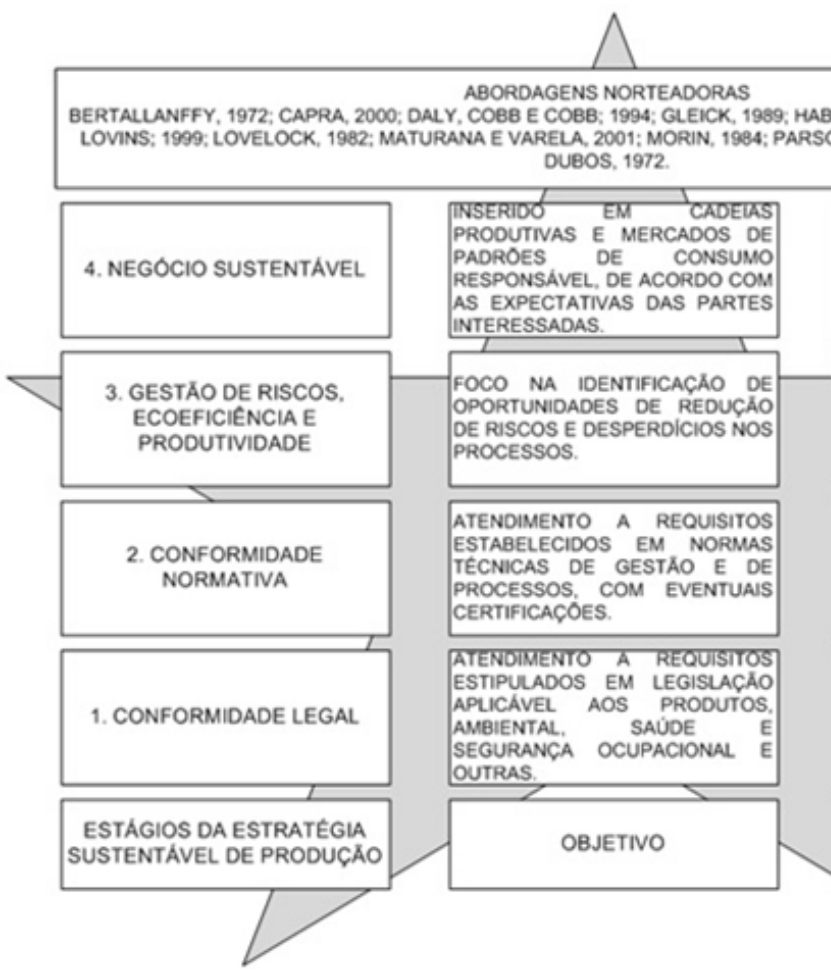

O primeiro estágio, Conformidade Legal, estabelece a seguinte premissa: a organização em busca da sustentabilidade deve atender integralmente aos requisitos estabelecidos pela legislação relacionada aos processos e produtos, aspectos socioambientais e riscos ocupacionais, entre outras aplicáveis. A abordagem proposta contempla o atendimento pleno da legislação com base em dois critérios: cálculo do custo do passivo legal decorrente da omissão e conformidade legal ao menor custo, conforme corroboram autores como Hey (1992), Brasil (2000), Machado (2013) e Silva (2002).

O segundo estágio, Conformidade Normativa, enuncia que a organização em busca da sustentabilidade deve atender requisitos estabelecidos em normas técnicas que constituem as melhores práticas de gestão e de processos disponíveis, de forma que seja possível a estabi- lização dos processos e sua medição por indicadores, de acordo com o proposto por Bandeira (2009), Chehebe (1998), Costa (2010), Harrington (1993), Juran (1993) e Kinlaw (1997), considerando apenas os principais ou mais clássicos autores sobre o tema. Os sistemas de gestão utilizados nesse estágio podem ser direcionados aos relacionamentos estratégicos da organização, como por exemplo, mercado e clientes (NBR ISO 9.001:2008), meio ambiente (NBR ISO 14.001:2004), saúde e segurança dos trabalhadores (OHSAS 18.001:2007) e responsabilidade social (NBR 16.001:2012). Deve-se destacar que as certificações podem proporcionar diferenciais de mercado para as organizações, porém, não são obrigatórias para o atendimento dos "requisitos" do estágio de Conformidade Normativa.

O terceiro estágio Fonte: Autores concentra-se na Gestão de Riscos, Eficiência e Produtividade e possui foco direcionado à redução de riscos, de custos e de desperdícios nos processos organizacionais. Toda forma de poluição, por exemplo, deve ser entendida como manifestação de ineficiência dos processos produtivos. O que para uma organização tradicional é visto como um problema deve ser percebido como uma oportunidade de melhoria de competitividade. Para tanto, cada intervenção é planejada e tem sua viabilidade definida de acordo com a análise de aspectos socioambientais e riscos ocupacionais, tecnologias apropriadas e investimentos associados, conforme preconizam Amaral (2005) De Cicco e Fantazzini (1985), Pauli (1996), UNIDO/ UNEP (1995), SENAI/RS (2003) e ISO (2009). Essa abordagem permite constatar que as maiores oportunidades existentes estão fortemente associadas ao aumento de produtividade, à redu- 
ção dos riscos e dos desperdícios dos processos.

O quarto estágio, Negócio Sustentável, dirige-se à cadeia produtiva completa, abrangendo desde os fornecedores até os clientes e consumidores. Entre as iniciativas estão as do tipo "efeito dominó" sobre a cadeia de fornecedores, que levam estes a adotar as práticas de sustentabilidade já adotadas pela própria organização, porém, adaptado à suas realidades. Outro elemento fundamental é a comunicação com os clientes e consumidores sobre as características dos produtos. Devem ser destacadas suas potencialidades, mas também suas limitações durante e após o uso, os indicadores de produção e outras informações que podem ser importantes para as partes interessadas. Em síntese, a transparência da organização leva a um melhor relacionamento com os grupos de interesse e, consequentemente, proporciona maior legitimidade social à organização, o que é tratado por autores como Almeida (2002), Drucker (1998), Freeman, Wicks e Parmar (2004), Keinert (2007), Leite (2009), Ligteringen (2012), Mazur e Miles (2010), Trías De Bes e Kotler (2011) e ainda Zylbersztajn e Lins (2010).

\section{CONSIDERAÇÕES FINAIS}

Como se percebe, não basta a organização "olhar para dentro" para alcançar a sustentabilidade. É fundamental que se inicie a busca pela sustentabilidade em caráter interno, mas a inserção de uma organização em uma cadeia produtiva e as características gerais dessa cadeia de fornecedores e consumidores dizem muito sobre o real estágio de sustentabilidade alcançado pela mesma.

O setor empresarial moderno tem evoluído rapidamente na busca da sustentabilidade, impulsionado em grande medida pelos desejos e tendências dos consumidores, que cada vez mais recorrem a valores da cidadania, como ética, justiça e transparência, para tomarem suas decisões de compra.

No Brasil, como no mundo, a vanguarda do setor empresarial não está alheia a essas mudanças e tem procurado corresponder, apren- dendo a pensar e a agir nas cinco dimensões da sustentabilidade, mesmo que sem a adoção de sequências ou roteiros sistematizados de ações coerentes entre o discurso e a prática, justamente a intenção de contribuição desse texto.

A partir da configuração geral de Sachs (2000) sobre as dimensões da sustentabilidade e corroborando a própria visão do autor de que o ideal será quando se falará somente em desenvolvimento, sem o prefixo eco, o texto propõe uma fundamentação de estratégias e instrumentos e uma reflexão sobre uma sequência de "Estágios da Estratégia Sustentável de Produção" como um possível caminho que seja útil a empresários, porém, por outro lado, que possa servir à própria sociedade (cidadãos e consumidores) para avaliar as práticas divulgadas por organizações que, ainda um pouco longe de cumprir com suas obrigações mais básicas, utilizam campanhas publicitárias para comunicar ao mercado que são sustentáveis.

Por fim, é importante ressaltar que quando falamos de organizações e negócios sustentáveis, estamos falando de pessoas sustentáveis.

\section{REFERÊNCIAS}

ABNT ASSOCIAÇÃO BRASILEIRA DE NORMAS TÉCNICAS. ABNT NBR 16.001:2012: Responsabilidade social - Sistema da gestão - Requisitos. Rio de Janeiro: ABNT, 2011.

ABNT ASSOCIAÇÃO BRASILEIRA DE NORMAS TÉCNICAS. NBR ISO 9.001:2008: requisitos. Rio de Janeiro: ABNT, 2008.

ABNT ASSOCIAÇÃO BRASILEIRA DE NORMAS TÉCNICAS. NBR ISO 14.001:2004: sistemas de gestão, especificação e diretrizes para uso. Rio de Janeiro: ABNT, 2004.

ALMEIDA, F. O bom negócio da sustentabilidade. Rio de Janeiro: Nova Fronteira, 2002.

AMARAL, S. Sustentabilidade Ambiental, Social e Econômica nas Empresas: como entender, medir e 
relatar. 2 ed. São Paulo: Tocalino, 2005.

AMATO NETO, J. Os Desafios da Produção e do Consumo sob Novos Padrões Sociais e Ambientais. In: AMATO NETO, J. Org. Sustentabilidade e Produção: teoria e prática para uma gestão sustentável. São Paulo: Atlas, 2011.

BANDEIRA, A. A. Indicadores de Desempenho: instrumentos à produtividade organizacional. Rio de Janeiro: Qualitymark, 2009.

BARROS, B. PRATES, M. O estilo brasileiro de administrar. São Paulo: Atlas, 1996.

BASSANI, P.; DE CARVALHO, M. A. V.. Pensando a sustentabilidade: um olhar sobre a Agenda 21. Desenvolvimento e Meio Ambiente, n. 9, p. 69-76, jan./ jun. 2004.

BATALHA, M.O., Sistemas agroindustriais: definições e correntes metodológicas, In: BATALHA, M.O. et. al, Gestão Agroindustrial, São Carlos : Ed. Atlas, 1997. P.24-48.

BRASIL. Ministério do Meio Ambiente. Convenção sobre diversidade biológica. Brasília, 2000.

CALDAS, M. Santo de casa não faz milagre: condicionamentos nacionais e implicações organizacionais pela figura do "estrangeiro". In: PRESTES MOTTA, F. C.; CALDAS, M. Cultura organizacional e cultura brasileira. São Paulo: Atlas, 1997.

CHEHEBE, J.R.B. Análise do Ciclo de Vida de Produtos: Ferramenta Gerencial da ISO 14.000. Rio de Janeiro: Qualitymark. 1998.

CHING, H. Y. Gestão de estoques na cadeia de Logística Integrada. 3. ed. 5 reimpressão. São Paulo: Atlas, 2009.

CLARK, T.; GREATBATCH, D. Management Fashion as Image-Spectacle The Production of Best-Selling Management Books. Management Communication Quarterly, v. 17, n. 3, p. 396-424, 2004.

COLLINS, D. Management fads and buzzwords: Cri- tical-practical perspectives. Psychology Press, 2000.

COLLINS, C. James e PORRAS, I. Jerry. Feitas para durar - Práticas bem-sucedidas de empresas visionárias. Rio de Janeiro: Rocco, 1996.

COSTA, N. P. Análise do Resultado Empresarial: principais ferramentas da análise corporativa. Rio de Janeiro: Ciência Moderna, 2010.

DE ALMEIDA JR, J. M. G. Um novo paradigma de desenvolvimento sustentável. Brasília: Câmara dos Deputados, 2000.

DE CAMARGO, S. X.; PINHEIRO, A. C. D. Fundamentação Ética do Desenvolvimento Sustentável em Kant, Habermas e Hans Jonas. Revista do Direito Público, v. 5, n. 2, p. 177-193, 2010.

DE CICCO, F.; FANTAZZINI, M. L. Técnicas modernas de gerência de risco. São Paulo: IBGR, 1985.

DE PAULA, A. P. P.; WOOD JR, T. Viagem epistemológica às livrarias dos aeroportos. Administração em Diálogo, São Paulo, n`5, 2003, p. 77-86.

DRUCKER, P. Administrando para Obter Resultados. São Paulo: Pioneira, 1998.

ENGLUND, T.; ÖHMAN, J.; ÖSTMAN, L. Deliberative communication for sustainability?: A Habermas-inspired pluralistic approach. In: Sustainability and security within liberal societies: Learning to live with the future. London: Routledge, 2008.

FIGUEIREDO, P.J.M. A sociedade do Lixo - os resíduos, a questão energética e a crise ambiental. Piracicaba, Ed. UNIMEP, 1995. 240 p.

FREEMAN, R. E.; WICKS, A. C.; PARMAR, B. Stakeholder Theory and "The Corporate Objective Revisited". Organization Science; 15, 3. p. 364-369. 2004.

FURTADO, J.S. Produção Mais Limpa e Ecoeficiência em Processos. www.vanzolini.org.br/areas/desenvolvimento/producaolimpa . 2 de julho de 1999.

GLEICK, J. Caos: a criação de uma nova ciência. Rio 
de Janeiro: Campus, 1989.

HABERMAS, Jürgen. Para o uso pragmático, ético e moral da razão prática. Estudos Avançados. 1989, vol.3, n.7, pp. 4-19.

HARRINGTON, J. Aperfeiçoando processos empresariais: estratégia revolucionária para o aperfeiçoamento da qualidade, da produtividade e da competitividade. São Paulo, MakronBooks, 1993.

HAWKEN, P.; LOVINS, A. B.; LOVINS, L. H. Capitalismo natural. Editora Cultrix, 1999.

HEY, E. The precautionary concept in environmental policy and law: institutionalizing caution. Georgetown International Environmental Law Review, Washington, n 4, p. 303-312, 1992.

ISO International Organization for Standardization. ISO 31000:2009: Risk management -- Principles and guidelines. ISO/TMB, 2009.

JURAN, J.M. Juran na liderança pela qualidade: um guia para executivos. 2 ed. São Paulo: Pioneira, 1993.

KEINERT, T. M. M. Org. Organizações sustentáveis: utopias e inovações. São Paulo: Annablume, 2007.

KINLAW, D.C. Empresa competitiva e ecológica: estratégias e ferramentas para uma administração consciente, responsável e lucrativa. São Paulo, Makron Books, 1997.

LEITE, P. R. Logística reversa: meio ambiente e competitividade. 2 ed. São Paulo: Pearson Prentice Hall, 2009.

LERIPIO, A. A. GAIA - Um Método de Gerenciamento de Aspectos e Impactos Ambientais. 2001. Tese (Doutorado em Engenharia de Produção) - Programa de Pós-Graduação em Engenharia de Produção da Universidade Federal de Santa Catarina (UFSC), Florianópolis.

LIGTERINGEN, E. Caminhando e conversando: stakeholders, juntos, a caminho de uma economia verde. In: ALMEIDA, F. Org. Desenvolvimento sus- tentável 2012-2050: visão, rumos e contradições. Cap. 2. Rio de Janeiro: Elsevier, 2012.

MACHADO, P. A. L. Direito ambiental brasileiro. 21 ed. São Paulo: Malheiros, 2013.

MAIA, C. M. As dimensões da sustentabilidade e a multifuncionalidade da agricultura familiar. In: II Seminário de Sustentabilidade do Centro Universitário Franciscano, 2007, Curitiba. Anais...Curitiba: FAE, 2007.

MANZINI, Ezio; VEZZOLI, Carlo. O desenvolvimento de produtos sustentáveis: os requisitos ambientais dos produtos industriais. São Paulo: Edusp, 2005.

MARTINE, G. O lugar do espaço na equação população/meio ambiente. Rev. bras. estud. popul. 2007, vol.24, n.2, p. 181-190.

MATURANA, H.; VARELA, F. A árvore do conhecimento: as bases biológicas da compreensão humana. São Paulo: Palas Athena, 2001.

MAZUR, L.; MILES, L. Conversas com os mestres da sustentabilidade. São Paulo: Gente, 2010.

MISSIAGGIA, R.R. Gestão de resíduos sólidos industriais - Caso da Springer Carrier. 2002. 127 f. Dissertação (Mestrado em Administração) - Escola de Administração, Universidade Federal do Rio Grande do Sul, Porto Alegre, 2002.

MOURAD, A. L.; GARCIA, E. E. C.; VILHENA, A. Avaliação do Ciclo de Vida: Princípios e Aplicações. Campinas: CETEA/CEMPRE, 92p. 2002.

MUNCK, L.; SOUZA, R. B. de. O ecletismo do paradigma da sustentabilidade: construção e análise a partir dos estudos organizacionais. Revista de Ciências da Administração, v. 13, n. 29, p. 202-242, 2011.

OLIVEIRA, João Hélvio Righi de. M.A.I.S.: Método para avaliação de indicadores de sustentabilidade organizacional. 2002. 196 f. Tese (Doutorado em Engenharia de Produção) - Engenharia de Produção, Programa de Pós-Graduação em Engenharia de Produção, Universidade Federal de Santa Cata- 
rina - UFSC.

OSHA Health and Safety Manual. OHSAS 18.001:2007: Health \& Safety Standard. OSHA, 2007.

PAULI, G. Emissão Zero: A busca de novos paradigmas: O que os negócios podem oferecer à sociedade. Porto Alegre, EDIPUCRS. 1996.

PAULI, Gunter. Upsizing: como gerar mais renda, criar mais postos de trabalho e eliminar a poluição. Porto Alegre: Fundação Zeri Brasil, 1998.

PEDROZO, E. A.; HANSEN, P. B. Clusters, Filière, Supply Chain, Redes Flexíveis: uma Análise Comparativa. Revista Análise - PUCRS - FACE, Porto Alegre, v.12, n. 2, p. 7-19, 2001/2.

PIERCE, J. L.; NEWSTROM, J. W. A estante do administrador: uma coletânea de leituras obrigatórias. Porto Alegre: Bookman, 2002.

PIRES, M.de S. Construção do Modelo Endógeno, Sistêmico e Distintivo de Desenvolvimento Regional e a sua validação através da Elaboração e da Aplicação de uma Metodologia ao Caso do MERCOESTE. 2001. Tese (Doutorado em Engenharia de Produção) - Programa de Pós-Graduação em Engenharia de Produção da Universidade Federal de Santa Catarina (UFSC), Florianópolis.

PRATES, G. A. (1998). Ecodesign utilizando QFD, métodos Taguchi e DFE. Tese (Doutorado em Engenharia de Produção) - Universidade Federal de Santa Catarina, Florianópolis, 1998.

RAMOS, G. Administração e contexto brasileiro. Rio de Janeiro: FGV, 1983.

RIGOLA, M. R., Producción mas limpia, Fondo Gallego de Coopieración y Solidariedad, 1998, disponível em http://www.igadi.org/index.html Acessado em 28/04/2008.

SACHS, I. Caminhos para o desenvolvimento sustentável. Rio de Janeiro: Garamond, 2000.

SACHS, I. Estratégias de Transição para o Século XXI: Desenvolvimento e Meio Ambiente. São Paulo:
Studio Nobel/Fundap, 1993.

SCHMIDHEINY, Stephan. Mudando o Rumo: Uma Perspectiva Empresarial Global sobre o Desenvolvimento e Meio Ambiente. Rio de Janeiro: Fundação Getúlio Vargas, 1992.

SENGE, P. et al.. Learning for Sustainability. Massachusetts: The Society for Organizational Learning, 2006.

SENAI-RS. Implementação de Programas de Produção mais Limpa. Porto Alegre, Centro Nacional de Tecnologias Limpas SENAI-RS/UNIDO/INEP, 2003.

SERVA, M. Contribuições para uma teoria organizacional brasileira. Revista de Administração Pública, v. 24, n², p. 10-21, 1990.

SILVA, G. E. do N e. Direito ambiental internacional: meio ambiente, desenvolvimentosustentável e os desafios da nova ordem mundial. 2 ed. Rio de Janeiro: Thex, 2002.

SIMÕES, J.C.P. A logística reversa aplicada à exploração e produção de petróleo. Dissertação (mestrado) - Universidade Federal de Santa Catarina, Centro Tecnológico. Programa de Pós-Graduação em Engenharia de Produção.

SLACK, Nigel et. al. Administração da produção. São Paulo: Atlas, 1997

TRÍAS DE BES, F.; KOTLER, P. A Bíblia da Inovação. São Paulo: Leya, 2011.

UNIDO/UNEP. Cleaner production assesment manual. Draft, 1995.

WARD, B.; DUBOS, R. Only One Earth: The Care and Maintenance of a Small Planet. Nova lorque: Norton Company, 1972.

ZYLBERSZTAJN, D.; LINS, C. Org. Sustentabilidade e geração de valor: a transição para o século XXI. Rio de Janeio: Elsevier, 2010. 